\title{
Em busca da identidade dos instrumentos musicais no Brasil: um estudo exploratório da literatura de cordel
}

\author{
Aloísio Leoni Schmid ${ }^{1}$ \\ Juarez Bergmann Filho' \\ Rodrigo Mateus Pereira ${ }^{3}$
}

RESUMO: O presente trabalho procura, em consulta a uma coleção de 2340 obras da Literatura de Cordel, explorar identidades culturais presentes nos instrumentos musicais aparentemente mais populares junto à população cultora de tal forma literária - sertão nordestino e parte da Região Norte do Brasil - desde o final do século XIX até o presente. Há no trabalho o pressuposto de que a Literatura de Cordel representa, muito mais que o trabalho criativo dos seus autores, as práticas vigentes no grupo social que a origina. Assim, à procura de menções a instrumentos musicais, este estudo detém-se em alguns deles, pela frequência e relevância da sua caracterização: viola caipira, violão, violino, bandolim, rabeca, guitarra elétrica e piano. Instrumentos aparentemente próximos como a viola e o violão são vistos de formas muito distintas pela população considerada. A rabeca, instrumento popular, poucas vezes é citada. Outros instrumentos, como violino, bandolim, piano e guitarra elétrica, são retratados como instrumentos urbanos e menos conhecidos.

PALAVRAS-CHAVE: Literatura de Cordel. Instrumentos musicais. Cantoria. Viola caipira. Luteria.

ABSTRACT: Based on a collection of 2340 poems, the present article aims to explore the identity of musical instruments considered most popular by the printed Literatura de Cordel (Cordel Literature) in the countryside of Northeastern and Northern regions of Brazil, from the end of the 19th Century to present days. The Cordel Literature is known for representing the views of the social group from which it is originated rather than the creative work of its poets/writers. In search of musical instruments mentioned in the text, some of them were selected due to frequency and relevance of the context found: e.g. the Brazilian viola (a five course guitar), the violão (the six string guitar), the violin, the mandolin, the rabeca (Brazilian fiddle), the electric guitar and the piano. The violão and the Brazilian viola, which are similar in shape, are seen by that population in quite different ways. The fiddle is a popular instrument, but had only a few mentions. Other
1. Docente da Universidade Federal do Paraná. E-mail: <aloisio.schmid@ gmail.com>.

2. Docente da Universidade Federal do Paraná. Email: <juarezbergmann@ gmail.com>.

3. Docente da Universidade Federal do Paraná. Email: <rodrigomateus@ufpr.br>. 
4. Brito (2009); Diegues (1973); Lamas (1973); Negrão (1975); Oliveira (2012); Queiroz (2006). instruments like the violin, the mandolin, the piano and the electric guitar are described as urban instruments, thus less known in that context.

KEYWORDS: Cordel Literature. Musical Instruments. Cantoria. Brazilian Viola. Lutherie.

Introdução

Entre os instrumentos musicais mais conhecidos da população rural do Nordeste do Brasil, figuram a viola caipira, o violão, o piano, o violino, o pífaro, a rabeca, a gaita e a zabumba. Ao menos, é o que indica a Literatura de Cordel, que existe desde o final do século XIX e cuja produção segue até os dias de hoje, na faixa rural que se estende, originariamente, desde o interior da Bahia até o Pará. É poesia autoral, mas os poetas, mais que autores, são porta-vozes das pessoas muitas vezes analfabetas - a quem se dirigem: reproduzem suas histórias, fatos, opiniões e práticas de um povo; daí sua popularidade. Esse gênero literário, que, em princípio, não resulta da criatividade individual, traduz o pensamento de um grupo social. Além dos temas cotidianos como amizade ou amor, fala da vida rural; da política; da música e, aqui, de particular interesse, de instrumentos musicais.

A Literatura de Cordel vem sendo estudada pelo menos desde 1921, ano da publicação de "Ao som da viola" por Gustavo Barroso. Escritores consagrados se dedicaram ao tema: Orígenes Lessa, Sílvio Romero, Câmara Cascudo e Ariano Suassuna bem como cientistas de diferentes áreas como a Linguística, a Música e a Sociologia. ${ }^{4}$ Esses trabalhos apontam algumas características da Literatura de Cordel, como: oralidade (não sem efeito pelo fato da impressão); popularidade; não erudição, comumente associada a artistas e/ou ouvintes analfabetos; não mercantilista; conservadorismo; paralelismo em outras regiões e continentes e em outras épocas (notadamente, a Europa Medieval).

Desde 2009, a Luteria é, no Brasil, objeto de um curso superior, fato que tem renovado o interesse acadêmico pelos instrumentos musicais. Uma questão de pesquisa surgida nesse artigo é sobre a relação de identidade a partir de diferentes instrumentos musicais para a população. Outras questões pertinentes: será que instrumentos musicais assumem papéis predeterminados? Que associações são evocadas com ideias, crenças, valores? Como sujeitos se identificam ao se relacionarem com artefatos musicais? 
$\bigcirc$ presente trabalho se propôs a refletir sobre essas perguntas a partir de um levantamento no acervo de Literatura de Cordel disponível na forma digital na Fundação Casa de Rui Barbosa, no Rio de Janeiro. ${ }^{5}$ Eram 2340 títulos no momento do levantamento: provavelmente, uma amostra estatisticamente significativa. Foram anotadas e analisadas todas as menções feitas aos instrumentos musicais acima relacionados. Foram encontradas algumas claras tendências na representação social dos instrumentos musicais para a população do sertão do Nordeste brasileiro, no período abrangido pela metade da penúltima década do século XIX até o presente.

A Literatura de Cordel como forma de acesso a uma identidade nos instrumentos musicais

Para o contexto deste artigo, entende-se identidade como um sistema de representação simbólico e performático da relação entre sujeitos, artefatos, memórias, tradições, lugares, espaços em seus sistemas de produção, circulação e uso. Entendese também que este complexo processo está em constante atualização e assim deve ser analisado dentro de um contexto espaço-temporal definido.

Segundo Garcia Canclini:

Quando se define uma identidade mediante um processo de abstração de traços llíngua, tradições, condutas estereotipadas), frequentemente se tende a desvincular essas práticas da história de misturas em que se formaram. Como consequência, é absolutizado um modo de entender a identidade e são rejeitadas maneiras heterodoxas de falar a língua, fazer música ou interpretar tradições. Acaba-se, em suma, obturando a possibilidade de modificar a cultura e a política. ${ }^{6}$

Como observou o etnomusicólogo Kevin Dawe, instrumentos musicais são tão emblemáticos e simbólicos das pessoas e dos lugares como qualquer outro fenômeno musical; $;$ assim sendo, instrumentos musicais seriam mais que ferramentas de produção sonora, mas representativos de culturas, ideias, e relações políticas e sociais em diferentes esferas humanas.

Ainda para Dawe, o grande desafio de se estudar a cultura dos instrumentos musicais é entender como as pessoas e seus artefatos são representados, mal representados ou ainda não representados.

Tratando-se da relação da música, da oralidade e da produção de instrumentos musicais, tal processo se mostra especialmente desafiador, dada a natureza transitória e efêmera de alguns de seus elementos, como a música de tradição oral e as questões relacionadas ao seu registro e reprodução.

Segundo o etnomusicólogo Eliot Bates, instrumentos musicais podem ocupar posições centrais nas redes sociais humanas. Além disso, eles próprios se tornam atores que medeiam relações humanas. A respeito do trabalho de Kevin Dawe, Bates destaca que o autor nos revela a importância de se colocar
5. Este material pode ser acessado em $<$ http://acervos. casaruibarbosa.gov.br/>.

6. Garcia Ganclini (2013, p. XXIII).

7. Dawe (2011). 
8. Bates (2012).

9. Barroso (1921, p. 21).

10. Barroso (1921, p. 21).

11. Lamas (1973, p. 235).

12. Lamas (1973, p. 235).

13. Dias (2010)

14. Lamas (1973).

15. Breve menção a alguns títulos da amostra utilizada para o presente trabalho revela isto: Swing, o sexo dos chifrudos, O rapaz que se apaixonou por outro, por força de bruxaria, Alcoolismo, maior inimigo do homem, Deus fez bomem e o diabo fez o macaco, Devassidão de hoje em dia, Protestante que foi expulso do céu, Quem ama mulher casada não tem vida segura. os instrumentos musicais como objetos e sujeitos de pesquisa. Segundo Bates, caminhamos ao estudo dos artefatos incorporados, incluindo os significados simbólicos e afetivos em instrumentos musicais. A isso, Bates denomina "pensar através de instrumentos musicais" ("thinking through instruments").

A dinâmica dessas representações pode parecer contraditória, dependendo de contextos de leitura, porém, pretende-se aqui evidenciar algumas constâncias nas representações simbólicas de artefatos musicais.

Desse entendimento, irrompe a questão de pesquisa: que viabilidade tem a tentativa, aqui proposta, de explorar identidades culturais contidas nos instrumentos musicais por meio da Literatura de Cordel, incluída no conceito mais amplo de Romanceiro Popular Nordestino?

Barroso já apontava possível resposta à questão na primeira obra registrada a estudar Literatura de Cordel, afirmando que "(...) a alma de uma raça inteiramente se resume nas suas trovas alegres ou tristes. Com effeito (sic), em todas as manifestações do "folk-lore» dum paiz (sic), a terra collabora (sic) com o homem". 9 Há algo como um processo de composição coletivo:

Mal sabendo lêr ou não o sabendo de todo, não tendo nenhum outro meio de communicação do pensamento, creou canções. A ausência do habito de leitura, deu a essas producções, às mais das vezes, formas que permittem ser facilmente guardadas, recitadas ou cantadas. ${ }^{10}$

No seu capítulo sobre música do livro Literatura Popular em Verso: Estudos, Lamas (1973) afirma que "(...) a música do Nordeste brasileiro, é óbvio, reflete $\mathrm{o}$ gênero de vida da região. Os que cultivam a cantoria repente ou a narrativa vivem, quase sempre, confinados em zonas rurais, por isso mais insulados e menos sujeitos às mudanças do meio urbano ou industrializado". "1

Para a autora, a referida música mantém características únicas, enquanto a produção comercial segue por caminhos distintos.

Os anos 60 e 70 foram de notável penetração da indústria fonográfica, associada à popularização da televisão e à continuação da presença do rádio. Lamas ${ }^{12}$ percebe isso e, na obra Literatura Popular em Verso, chama a atenção para a diferença entre uma música que chama de folclórica e a música consagrada como popular, que seria voltada para o consumo das massas.

Dias ${ }^{13}$ oferece distinção semelhante: se a música caipira pertence às práticas do homem rural de forma orgânica, a música sertaneja já é considerada mercadoria.

Lamas $^{14}$ sublinha o caráter conservador da música folclórica. ${ }^{15}$ Para a autora, é mais um indício de que a produção dos cantadores não tem expressão própria, não atinge a fase de sublimação, de subjetividade da arte elaborada. Isso confere especial validade ao que comunica o artista popular:

É mais autêntico, é mais profundo o poder de comunicação do artista iletrado que, expressando-se com simplicidade, naturalidade, sem artifícios, tem logo ressonância no espírito do seu 
grupo. Há, evidentemente, na arte dos violeiros e repentistas uma perfeita identificação do artista com o seu auditório. Ele é produto do próprio meio, ele usa expressões, modismos perfeitamente assimiláveis pelos que o ouvem. Sua popularidade - dadas as naturais condições de vida comunitária - chega a confundir-se com solidariedade. ${ }^{16}$

Negrão, ${ }^{17}$ num artigo de abrangência a respeito da Literatura de Cordel, aproxima-se da Teoria das Representações Sociais de Moscovici, ${ }^{18}$ pois fala na mundivalência ${ }^{19}$ do artista e do seu grupo social. Esses traços fazem do romanceiro popular nordestino "(...) uma rica fonte para estudos sociológicos, psicológicos e literários, além de lingüísticos, no que concerne à fixação do aspecto brasileiro da língua portuguesa". ${ }^{20}$

Ao sublinhar que o poeta popular não representa uma individualidade, Negrão ${ }^{11}$ menciona, outrossim, o virtuosismo técnico desses poetas, autodenominados trovadores. E lembra que o cantador:

(...) desfia ao som da viola romances folclóricos, que todos já sabem mas que não se cansam de ouvir, e prova a sua mestria "versando" a última notícia importante; contando um "causo"' de sua lavra; glosando o tema ou mote dado na hora ou cantando numa "peleja" com outro cantador. ${ }^{22}$

Alves $^{23}$ também contrapõe dois conceitos de poesia: poesia popular, que é poesia de um autor que se sente povo; e poesia tradicional, que é poesia de um povo que se faz autor. A exemplo do que canta Rodolfo Coelho Cavalcanti: "Quem é vate do sertão / É Jornalista atuando / Na alma do próprio Povo, / Ao Povo doutrinando, / É Povo falando ao Povo / Na hora que está versando". ${ }^{24}$

Oliveira (2012) cita Mário de Andrade, que reforça tal visão: "(...) o artista popular é o mais intransigentemente funcional de todos os artistas, (...), que conserva em tudo o que ele é aqueles princípios mesmos que fizeram a arte nascer". ${ }^{25}$

A Literatura de Cordel tem claramente identificado, no Brasil, um momento inicial no final do século XIX, quando as primeiras impressões aconteceram por iniciativa de Leandro Gomes de Barros. ${ }^{26}$ A ideia teria sido trazida da Europa, começando-se a imprimir, de forma rudimentar, aquilo que outrora era apenas falado. Para Alves, ${ }^{27}$ disso cria-se "(...) uma literatura de mascate, de cordel, folhetos de feira (denominação popular) em um processo extremamente original, o que implica em (sic) dizer que onde nasce o verso, a origem é a voz". Uma ilustração de folhetos expostos em cordel numa feira está acima exemplificada.

Ainda na esteira de uma progressão do folclórico para o erudito, Alves $^{28}$ relata o que seria uma divisão de trabalho entre poetas e cantadores - estes, se valendo do poema impresso e caminhando em direção a uma cultura mais convencional, elaborada, mas abandonando o improviso e, com isso, uma maior autenticidade.

A respeito de paralelismos, Algeri \& Sibin, 29 pesquisando a origem da Literatura de Cordel, mencionam o linguista Mikhail Bakhtin. Para eles, todos os
16. Lamas (1973, p. 236).

17. Negrão (1975).

18. Moscovici (2003).

19. Expressão da autora citada: significação que se atribui a esse mundo.

20. Negrão (1975, p. 139).

21. Negrão (1975, p. 139).

22. Negrão (1975, p. 136).

23. Alves (2009).

24. Maxado; Cavalcante (1979).

25. Oliveira (2012, p. 70).

26. Moreira (1973).

27. Alves (2009, p. 1).

28. Alves (2009, p. 1).

29. Algeri; Sibin (2008). 
textos seriam ecos de outros textos: reescritos, reinventados, reaproveitados, de modo que a literatura estaria constantemente, em diferentes lugares e épocas, dialogando com esses ecos e sendo reescrita. Assim, iremos encontrar, no material analisado, referências vindas de outros continentes e de séculos remotos, bem como toda uma formação de identidade própria dos instrumentos musicais em solo brasileiro.

Materiais e métodos

Realizou-se um levantamento (survey) de caráter exploratório no universo de cordel digitalizado (2340 textos) no acervo da fundação Casa de Rui Barbosa. Mediante busca sistemática, cada uma das menções a instrumentos musicais foi lida e analisada no seu contexto. Inicialmente, fez-se uma contagem das menções para quantificar a presença de cada instrumento. Pela importância da viola, acrescentou-se a palavra violeiro. A Tabela 1 traz, na sua segunda coluna, as ocorrências registradas e, na terceira, a indicação resumida da análise. Os textos incluídos nesta tabela datam de 1909 a 2006.

Tabela 1 - Ocorrências de instrumentos musicais na amostra considerada

\begin{tabular}{|c|c|c|}
\hline TERMO & OCORRÊNCIAS & OBSERVAÇÃO \\
\hline rabecão & 4 & Sem significado especial \\
\hline maracá & 6 & Sem significado especial \\
\hline bandolim & 8 & Análise a seguir \\
\hline berimbau & 9 & Sem significado especial \\
\hline corneta & 10 & Sem significado especial \\
\hline flauta & 13 & Sem significado especial \\
\hline tambor & 15 & Sem significado especial \\
\hline guitarra & 17 & Análise a seguir \\
\hline zabumba & 19 & Sem significado especial \\
\hline pife & 24 & Sem significado especial \\
\hline violino & 25 & Análise a seguir \\
\hline cuíca & 25 & Sem significado especial \\
\hline rabeca & 31 & Sem significado especial \\
\hline piano & 31 & Análise a seguir \\
\hline sanfona & 32 & Sem significado especial \\
\hline chocalho & 40 & Sem significado especial \\
\hline apito & 47 & Sem significado especial \\
\hline pandeiro & 49 & Sem sificado especial \\
\hline gaita & 55 & Semociada a festas \\
\hline
\end{tabular}




\begin{tabular}{|c|c|l|}
\hline TERMO & OCORRÊNCIAS & OBSERVAÇÃO \\
\hline violeiro & 57 & Análise a seguir \\
\hline violão & 85 & Análise a seguir \\
\hline viola & 293 & Análise a seguir \\
\hline
\end{tabular}

Sobre esta tabela, deve-se observar que existem ocorrências repetidas, uma vez que o acervo digitalizado contém, por vezes, várias edições do mesmo texto, colecionadas por guardarem uma ou outra variação.

$\bigcirc$ instrumento com maior número de ocorrências é a viola caipira, ou simplesmente viola, ou ainda viola brasileira - não confundir com o instrumento de cordas a arco que, na família do violino, corresponde ao registro do contralto.

Em cada uma das ocorrências, leu-se toda a estrofe em que acontece e, quando necessário, as estrofes adjacentes. Foram buscadas associações: situação em que o instrumento musical é utilizado, a quem pertence, atributos da pessoa que o toca, como se dá o acesso a tal habilidade, além de outras informações. As ocorrências foram, então, organizadas de acordo com um ou mais aspectos que revelam.

Associações relevantes de papel desempenhado, caráter ou contexto foram identificadas com relação aos seguintes instrumentos: viola, violão, rabeca, violino, bandolim, piano e guitarra. Exceto a sanfona ${ }^{30}$ (de que se percebeu, conforme Tabela 1, ser instrumento usado nas festas, para embalar a dança), outros instrumentos apareceram antes soltos, sem aparente tendência e, por isso, nesse contexto, foram classificados como "sem significado especial". Esta pesquisa, assim, acabou ganhando um foco sobre os instrumentos de corda mais populares.

escopo físico é o Norte e Nordeste do Brasil, regiões em que se iniciou a disseminação, no final do século XIX, da Literatura de Cordel, e onde ela permanece como uma manifestação popular. Portanto, o período considerado inclui a última década do século XIX, a totalidade do século XX e seis anos iniciais do século XXI.

A seguir, a análise será feita para cada instrumento, procurando-se organizar as menções encontradas sob uma linha de raciocínio.

A viola, extensão do violeiro

Cascudo ${ }^{31}$ menciona a origem portuguesa da viola, primeiro instrumento de cordas que os portugueses divulgaram no Brasil, já que, no século XVI, tinha seu esplendor em Portugal, qual registrado por Gil Vicente.

A viola, na Literatura de Cordel, se torna personagem, e o cantador não raro dedica muitos versos ao próprio instrumento de trabalho. É, antes de mais nada, parte da indumentária, um equipamento obrigatório da vida social do
30. É importante esclarecer que a nomenclatura de alguns instrumentos pode gerar confusão de acordo com a região que está sendo contextualizado. Uma sanfona no Brasil é um instrumento aerófono, semelhante ao acordeão e bandoneon. Já em Portugal, a sanfona pode ser confundida com um cordófono a fricção, muitas vezes conhecido como Viola de Roda.

31. Cascudo (1973). 
32. Arêda (s.d., p. 1).

33. De Ataíde (1976, p. 7).

34. Cavalcanti (1959, p. 28).

35. Gonçalo Ferreira da Silva (2002, p. 5).

36. João Melquíades Ferreira da Silva (s.d., p. 3).

37. Resende (s.d., p. 7).

38. D'Almeida Filho (1958, p. 10).

39. Minelvino Francisco Silva (s.d., p. 8).

40. Minelvino Francisco Silva (s.d., p. 10).

41. De Ataíde (1947, p. 2).

42. Minelvino Francisco Silva (s.d., p. 11).

43. Minelvino Francisco Silva (s.d., p. 2).

44. Minelvino Francisco Silva (s.d., p. 28).

45. João Martins de Ataíde (1951, p. 2).

46. D'Almeida Filho (s.d., p. 22).

47. De Ataíde (1938, p. 33).

48. Minelvino Francisco Silva (s.d., p. 5).

49. Cavalcanti (1978, p. 1).

50. D'Almeida Filho (1979, p. 25).

51. D'Almeida Filho (1958, p. 23).

52. Pereira Sobrinho (s.d., p. 11).

53. Arêda (s.d., p. 2).

54. De Ataíde (1951, p. 2). trovador: "Peguei a viola e fui (...) já encontrei tudo em festa". 32 Um cego que é chamado a conhecer uma pretendente "Deixou em casa a sacola / Levou somente a viola / O cachorrinho e o guia". 33

Numa trova sobre o casamento, compara-se o casamento sem fidelidade a um cantador sem viola: "É um poeta sem ter rima / É um jogador sem ter bola / É um cantador sem ter viola". ${ }^{34}$ Em certa metáfora, como sinal de fidelidade, num cordel sobre o trovador Patativa do Assaré, faz-se menção a sua única viola. ${ }^{35}$

Dificilmente se menciona um determinado artista que seja somente cantor ou declamador, o que é considerado uma desvantagem e resulta em zombaria: "Meu Deus que cantor é este / Que sentou-se aqui falando / Sem viola e sem toada / Seu cantar é conversando". ${ }^{36}$ Ou ainda: "(...) se mette (sic) a querer cantar também / mas não tem p'ra (sic) cantar uma viola". ${ }^{37}$

A viola é, em si, objeto de apreciação, com valor intrínseco, visual ${ }^{38}$ ou musical:39 "Toque a viola (...) com o som desta viola (...). Ou ainda: "No som daquela viola / chegava a se desmanchar". ${ }^{40}$

E para que mais serve a viola como um obrigatório equipamento? Uma pista é dada pelo trecho: "Depois chegou o Campina / Com a viola na mão, / Pedindo ao povo da casa / 'Me aponte o valentão'". ${ }^{41}$ A viola é frequentemente apresentada, pois, como um acessório do trovador, com que desafia outro trovador, à guisa de duelo de pistoleiros: "Que venha com sua viola / que a coisa aqui está boa / venha as dez horas da noite / que hoje a poeira voa. ${ }^{42}$ Assim também em: "(...) na viola e na caneta / nunca aceitou indireta". ${ }^{43} \mathrm{Ou}$ ainda: "Rebento a viola dele / pra (sic) acabar seu furor / Ele tem que conhecer / Eu como superior". ${ }^{44} \mathrm{E}$ finalmente: "Seja livre ou seja escravo / eu quero cantar martelo / afine sua viola / vamos entrar em duelo / só com a minha presença / o senhor está amarelo". 45

que comumente é arma de duelo, aqui é arma de destruição em massa: "Na viola eu brigando venço cem". ${ }^{46}$ Um grupo de criminosos, nos momentos de lazer, permanece "(...) no terreiro vadeando / os bacamartes encostados / e numa viola tocando". 47

A viola se torna, então, assunto para feitos heroicos: "(...) com ele ninguém topava no estro da cantoria no tempêro da viola todo cantador corria". ${ }^{48}$ Ou ainda: "Eu sou bom sou importante / na caneta e no papel / toco viola improviso / no verso sou bacharel / sou a potência e a glória da poesia em cordel". 49

O uso da viola segue um ritual de que faz parte, como prelúdio, o momento da afinação. ${ }^{50,51,52}$

O trabalho de afinar a viola, ato necessário para se poder utilizá-la adequadamente, é ocasião necessariamente mencionada em muitas trovas que descrevem um encontro de dois cantadores: "Assim que entrei no salão / Logo a viola afinei (...) Porém nos primeiros versos / Todo agitado fiquei". ${ }^{53}$ É um momento de tensão, por vezes prolongado na narrativa, como no trecho já citado: "Afine a sua viola / Vamos cantar um duelo / Só com a minha presença / O senhor está amarelo". ${ }^{54} \mathrm{~A}$ essa fala, vem a resposta: "Vejo um vulto tão pequeno / Que nem o posso enxergar, / Julgo que nem é preciso / Nem a viola afinar". 
Por vezes, essa tarefa acaba expressando frieza, indiferença e até crueldade: "(...) só conheço o violeiro pela viola afinada e Só conheço o repentista / Depois do verso primeiro". 55

A posse ou a dignidade da viola podem se perder quando a derrota num duelo é marcada pela atitude do vencedor de quebrá-la na cabeça do perdedor: "Se acostume com pau e reconheça (...) the quebro a viola na cabeça". 56

Ou ainda numa troca de ofensas que contrapõe cantadores com diferentes graus de formação: "Gastaste prá te formar / Só doze anos de estudo / Eu estudei quinze anos / Te vejo muito miúdo / Vou fazer tú engolir / viola com corda e tudo".57

Outra atitude é a de o derrotado voluntariamente quebrar sua viola para nunca mais tocar, obrigando-se assim a ter de abraçar outra profissão: "(...) quebrou a viola nas pedras / e correu foi se embora (...) Não quis mais ser cantador". ${ }^{58}$ Em outro cordel, lê-se: "(...) o que me consola é te ver um dia / de vara e guia pedindo esmola". 59

Certo desafio desanda para a disputa de conhecimentos sobre a história: "E qual foi a $1^{a}$. guerra / Feita a barco a vapor? / Você ou diz ou apanha / Da surra muda de cor / Quebra a viola e deserta, / Nunca mais é cantador". 60

Mais um exemplo: "Deu-he um tremendo empurrão / e a viola arrebatou / disse: agora eu vou fazer / uma comédia colosso / com força pegou o pinho / deu na cabeça do moço / que a viola ficou /enfiada no pescoço". ${ }^{61}$

Ou ainda: "Rasgo roupa, arrebento-lhe a viola / Deixo ele implorando uma esmola (...)", a que o opositor responde: "Hoje eu faço tú comeres a viola / com bordão, com os trastes e craveira / com a prima, segunda e com terceira / Hoje aqui tua sorte descontrola / A cabeça no salão se desmiola / Eu te deixo na rua tresloucado". 62

Enfim, narrando o futebol em criativa metáfora: "O time do parque Antártica / aguentou um show de bola / Leão errou o repente / mandou quebrar a viola / e a cobra chegou aqui / com 3 pontinhos na sacola". ${ }^{63}$

A viola não apenas foi o instrumento mais frequentemente mencionado; também se constatou diversas ocorrências do vocábulo violeiro. Entre outros aspectos, isso permitiu identificar trecho de introdução a um volume de Cordel em que Antonio Justa procura descrever um típico violeiro. Embora destoe do material central ao presente trabalho, a descrição é útil para encaminhar a análise dos poemas:

Quase sempre desocupado, sem profissão classificada entre as classes laboriosas, boêmio por índole, valentão e desordeiro, seduzindo mulheres, dominando a canalha: eis o trovador do povo, a perambular de povoado em povoado, adivinhando casamentos e batizados, de viola ao peito, faca de ponta à cinta, lenço de ganga ao pescoço, cabelos em cachos sobre a testa, usando jaqueta e camisa muito anilada. ${ }^{64}$

Tocar viola, enquanto escolha, é atividade comumente associada a dom divino: "É muito feliz o homem / Que com tudo se consola / Posso
55. Cavalcanti; Maxado (1979, p. 2).

56. D'Almeida Filho (1979, p. 15).

57. Minelvino Francisco Silva, Peleja do filho do cego Aderaldo com o filho de Zé Pretinho (s.d.).

58. Minelvino Francisco Silva, Peleja do filho do cego Aderaldo com o filho de Zé Pretinho (s.d., p. 16).

59. De Ataíde (1940, p. 14).

60. Cavalcanti (1975, p. 9).

61. D'Almeida Filho (1958, p. 10).

62. Minelvino Francisco Silva (s.d., p. 13).

63. Soares (1978, p. 6).

64. Justa (1973, p. 3). 
65. De Ataíde (1951, p. 15).

66. Negrão (1975, p. 141).

67. Negrão (1975, p. 141).

68. Negrão (1975, p. 141).

69. Arêda (s.d., p. 2).

70. Vilela (2004, p. 181).

71. De Ataíde (1939, p. 5).

72. D'Almeida Filho (1958, p. 1). morrer na pobreza / Me achar pedindo esmola / Deus me dar para passar /Ciência e esta viola". ${ }^{65}$

Por outro lado, em curiosa contradição, para dominar a técnica da viola, muitas vezes é mencionada a necessidade de um pacto com o demônio, curiosamente inserido na visão de mundo fortemente católica e, para Negrão, 66 marcadamente maniqueísta: "(...) ○ Bem triunfa sempre ao final, sem contudo derrotar o Mal, que também renasce sempre". A Corte Celeste seria "(...) particularmente sedentária, comodamente instalada nos seus lugares consagrados, com alguma projeção da vida ociosa do senhor de engenho abastado, dono da terra e da vida de todo mundo pequeno à sua volta". .7 Enquanto isso, ocorre uma ação "(...) superdinâmica do Mal, sutil, dissimulado, insinuando-se em tudo e em toda parte". 68

E não há, na Literatura de Cordel, outro instrumento com que se relacione e enfrente o demônio como a viola. Ela comumente reflete o estrato social do postulante, evidenciando ainda tensões sociais, religiosas e raciais: "Nisso alguém falou na porta / Pediu licença e entrou / Era um negro estranho e feio / Que a todo mundo assombrou / Com uma viola velha / Junto de mim se sentou". 69 Não era ninguém menos que o diabo.

Aliás, há, de maneira geral, no Brasil, uma curiosa relação entre o divino e o profano, evidenciada pela Viola e seu Violeiro. São diversas as narrativas de violeiros que supostamente receberam seus dons artísticos a partir de pactos em encruzilhadas ou igrejas profanadas.

Curiosamente, o violeiro atrai para si uma aura de diferenciação, de misticismo, pois tocar viola com destreza é sempre visto como algo que salta aos olhos das pessoas e suscita curiosidades. E a habilidade no tocar é muitas vezes associada ao resultado de algum pacto. Assim, este violeiro mantém um trânsito do profano para o sagrado, e vice-versa, como nenhuma outra pessoa da comunidade consegue. Ele toca nas festas da igreja e faz o pacto com o tinhoso para tocar melhor e nem por isso é rechaçado do meio onde vive. ${ }^{70}$

Embora, em algumas passagens, possa se supor o contrário, uma visão mais geral do violeiro mostra que ele não é um fanfarrão e que sua existência parece ter um sentido maior. $\bigcirc$ violeiro tem uma missão especial neste mundo. Fadado a levar uma vida transitória entre o bem e o mal, sábio, sofredor, sedutor, herói popular como neste desafio, que também acaba se tornando uma disputa de conhecimento: "Infeliz do violeiro / que emprega sua cantoria / pra (sic) cantar sem resultado / coisas que não têm valia". ${ }^{71}$

Ou ainda numa obra em que o violeiro sugere semelhança a um herói de cinema, num tipo recorrente nos filmes western: "É uma história verídica / dum caboclo violeiro / sincero e trabalhador / corajoso e verdadeiro / com todos os requisitos / dum trovador brasileiro/ Porém não era briguento/ E mostrava educação / Embora fosse de berço / Porque não teve instrução / Guardava a coragem para / Quando houvesse precisão / Assim para todo mundo / Era covarde e medroso / Não teimava com ninguém / Era muito caprichoso / E não queria negócio / Com valente criminoso". ${ }^{72}$ 
Este sentido de vida do violeiro aparece como missão heroica, qual seja, tornar o Brasil um lugar mais justo: "Pra (sic) matuto ou chanceler / Para pobre ou usineiro / $\bigcirc$ cantador violeiro / Se apresenta onde quer". ${ }^{73}$

A possível inabilidade do adversário também pode ser usada para desqualificá-lo, o que comumente inclui o estado de sua viola, em que a falta de uma corda é ocasião para crítica e ataque: "Esse poeta sem rima / toca viola sem prima / não vale o que o gato enterra" ${ }^{74}$

E mais um exemplo do instrumento musical sendo desqualificado juntamente com seu dono: "Subo serra, desço morro / atraz dum cantador fraco / como esse Mané Pretinho / cuja viola é um caco". ${ }^{75}$

Tocar viola é atividade de que se tem orgulho: "Há muitos anos atrás / Fiz profissão da viola. ${ }^{76}$ Ou ainda: Eu canto há dezoito anos / Há vinte (sic) toco viola". ${ }^{77}$ A decisão por tocar viola não corresponde somente à de abraçar uma profissão; é caracterizada como ato de coragem, como se fosse a decisão de arriscar a própria sorte: "Antonio com sua viola / pelo mundo viajou / dinheiro roupa e comida / daí nunca mais faltou". ${ }^{78}$

poeta é, não raro, contraposto ao repetidor de folhetos, como no exemplo de Dimas Batista: "Basta um cabra não ter disposição / Pra (sic) viver do serviço de alugado, / Pega numa viola e bota ao lado, / Compra logo o Romance do Pavão, / A Peleja do Diabo e Riachão, / E a História de Pedro Malasarte, / Sai no mundo a gabar-se em toda parte, / E a barrar por vintém em meio da feira, / Parasitas assim desta maneira / É que têm relaxado a minha arte" .79

Tocar viola, aqui, é atividade preferencialmente associada à prática da poesia. Mas não existe caminho formal para se chegar a isso. Há quem faça simplesmente a apologia do gênio, como Maxado Nordestino, ao disputar com Rodolfo Cavalcante, seu antigo professor: "Quem nasce pra (sic) cantador / trás (sic) a viola na mão / tem o repente nos lábios / musa na inspiração / conhece bem a sextilha / na toada do baião". 80

Ou quem lembre a necessidade de uma escola de vida - fato que não necessariamente exalta a educação contraposta à genialidade, mas a experiência, em muitos contextos, contraposta à educação. "Caboquinho é repentista e também é trovador, / Lá em Feira de Santana se formou em Professor, / porém não deixa a viola que é a verdadeira / Escola do homem improvisador". ${ }^{81}$

E de onde saem música e versos? Aparentemente, da cabeça do trovador, como no exemplo: "Nesta cidade vivia cantando na sua viola tirando da sua caxola bons repentes e poesia". ${ }^{82}$ Ou ainda: "Minha mente é minha escola / o meu livro é minha viola". ${ }^{83}$

Isso não contradiz a informação de que o material (temas, opiniões, valores) que alimenta o poeta, salvo exceções (como o conhecimento escolar), tem origem oral e popular.

A viola também é associada ao cantador como parte da sua existência, ligada ao sentido de sua vida, de modo que o fim de um cantador também é o fim da sua viola: "Pareço perder a fé / Com a morte desta viola.
73. Santa Helena (1984, p. 6).

74. Soares (s.d., p. 7).

75. Minelvino Francisco Silva (s.d., p. 9).

76. D'Almeida Filho (1979, p. 1).

77. De Ataíde (1951, p. 8).

78. Minelvino Francisco Silva (s.d., p. 8).

79. Estrofe retirada da obra de Moreira (1973), e não do acervo da Fundação Casa de Rui Barbosa.

80. Maxado; Cavalcanti (1979, p. 6).

81. Cavalcanti (1977, p. 9). 82. Cavalcanti (s.d., p. 1). 83. Cavalcanti (1957, p. 2). 
84. Cavalcanti (s.d., p. 2)

85. Gonçalo Ferreira da Silva (s.d., p. 3).

86. Pereira Sobrinho (s.d., p. 25).

87. Swain (1995).

88. Resende (1979, p. 25).

89. D'Almeida Filho (s.d., p. 7).

90. Santa Helena (1993, p. 3).

91. Cavalcanti (1968, p. 3).

92. Cavalcanti (1968, p. 8)

93. Cavalcanti (s.d., p. 2).

94. D'Almeida Filho (1980).

95. D'Almeida Filho (s.d., p. 9).

96. Cavalcanti (1983b, p. 15).

97. Cavalcanti (1983a, p. 3).

98. Santa Helena (1988, p. 9).
/ Morreu Francisco Alves / Foi a notícia do dia / Os violões se calaram / No auge da melodia". ${ }^{84}$

O violão, o instrumento dos salões

Apresentamos o violão, em contraste à viola, como um instrumento de família: "Assim é que no aconchego / Feliz do lar tem à mão / um violão que dedilha / canalizando a emoção / ao reproduzir dos vates / toada, acorde e baião". 85

Se não é da família, é, no mínimo, um instrumento do salão. Possível especular que o fato de ser ali mencionado decorra da necessidade de uma rima: "Todo instrumento de música / encontrou em um salão / ele que apreciava / pegou logo um violão / afinou ao seu jeito / e cantou uma canção". 86 Mas outros exemplos apontam que não.

violão é um instrumento quase que exclusivo de instrumentistas mulheres (enquanto muito raramente se associa viola à mulher). Aqui, os cordéis mostram coerência com o que afirma Mc Swain ${ }^{87}$ a respeito do papel do violão (contraposto à guitarra elétrica) nos Estados Unidos. Considere-se o trecho: "(...) estava n'outro salão / moças cantando modinha / ao som de um violão". 88

O violão é mencionado em passagem em que descreve os dotes de uma moça: "Aprendeu cantar modinhas / e tocar bem violão". 89

O violão também é a opção musical de um refinado artista, Vinícius de Moraes: "Trocou teclas do piano / por violão afinado". 90

Violão se aprende, e num meio particular, não da forma em que se aprende a viola. Como se conta de Catullo da Paixão Cearense: "Do velho Amâncio escondido / Fazia suas Serenatas / Até que foi instruído / para tocar violão / iá na terceira lição / tinha as regras aprendido". ${ }^{91}$

Considere-se o trecho: "Carmosina era uma jovem / da mais fina educação / acordou-se sacudida / pelo som do violão / pelas estrofes da valsa / na triste lamentação". 92 "Com violão se (sic) acompanha uma serenata"; 93 "(...) se (sic) toca também uma balada"; 94 se toca uma música para se ouvir, destacada do texto (o que não seria possível na cantoria): "Pelo pensamento ouvia / aquela valsa-canção / entrando pelos ouvidos / com o som do violão". 95 Difere da viola; tanto que encontramos Rodolfo Coelho Cavalcanti especificando "Um cordel para ser cantado / nas cordas de um violão". 96

Outro exemplo de violão em ambiente mais sofisticado: "Bebe Wisque com o Doutor / Itamar, e Abdias / ao lado, vão comer / uma peixada no Alfredo, / em céu estrelado, / ao som de um violão". 97

Num texto que explora as transformações da cultura nordestina numa cultura urbana e regionalmente indiferenciada, Raimundo Santa Helena inclui, naturalmente, a escolha dos instrumentos musicais: "Troquei pife por pistão; / recoreco e rabeca / por moderno violão". 98 
Por fim, o violão é repetidas vezes lembrado como metáfora do corpo feminino (a viola, não): "Menina muito faceira / de corpinho violão". 99

bandolim: semelhante ao violão

Como o violão, aparece como instrumento melódico, não necessariamente associado à tarefa de acompanhar o canto.

Aqui, fala-se de uma menina que "Se (sic) divertia tocando, / Num sonoro bandolim". ${ }^{100}$

Aparece também como o instrumento de um poeta "Que passava sempre as noites / Cumprindo o seu triste fado / Ao som de um bandolim / Como um pobre despresado (sic)". ${ }^{101}$

Seu som é associado a fantasia: "E ao som do bandolim / Todas sereias cantavam / Uma valsa tão penosa / Que até os peixes choravam. ${ }^{102} \mathrm{Ou}$ em: Sapo tocava guitarra, $\bigcirc$ macaco, bandolim". ${ }^{103}$

São, enfim, poucas as menções que sugerem que o bandolim seja instrumento de som exótico, porém, raramente ligado a alguma situação real. Não parece ser algum instrumento conhecido.

piano: instrumento das donzelas

piano aparece, geralmente, como um instrumento refinado. De início, é tratado como uma das invenções do homem, artista: "Rádio, vitrola e Piano / Tanque de guerra e motor / Milhares de invenções / Foi o artista inventor". ${ }^{104}$

Como instrumento, está acima da viola, para Catullo da Paixão Cearense, ${ }^{105}$ à altura do violino.

Um cordel que fala de urbanização de um personagem menciona a troca de "Acordeom por piano(...)". ${ }^{106}$

Piano é algo que se aprende formalmente: "(...) requer uma professora". ${ }^{107}$ Das referências ao piano, predominam aquelas feitas no contexto da educação de uma menina ou moça, geralmente associada ao estudo de idiomas, corte e costura ou outra habilidade. Pois tocar piano parece habilidade essencial para que uma donzela conquiste um cavalheiro: "Ela tocou no piano / Afim de obsequiá-lo". ${ }^{108}$ Ou ainda: "Cosette escrevia bem, / Sabia tocar piano; / Bordava bem e cosia". 109

piano realça situações de afirmação social de moças formosas que superavam alguma barreira: o fato de serem escravas como Isaura "Isaura aos quinze anos / Sabia ler e escrever / Tocar piano e dançar / Cortar, bordar e coser,/ E então serviços domésticos /Tudo sabia fazer" 110 ou Guiomar "Mandou ensinar piano / Inglês, francês, alemão / Lapidando aquela jóia / A flor do seu coração"; 11 de o amante Oscar ser negro "Aurora foi ao piano
99. Cavalcanti (s.d., p. 1). 100. De Ataíde (1951, p. 6) 101. Resende (1979, p. 5) 102. Pacheco (1979, p. 15). 103. Do Amaral (s.d., p. 9) 104. Cavalcanti (s.d., p. 7). 105. Cavalcanti (1973, p. 19) 106. Santa Helena (1988). 107. Pereira Sobrinho (1959, p. 31).

108. De Ataíde (1950, p. 8). 109. Pereira Sobrinho (s.d., p. 59).

110. Batista (s.d., p. 3).

111. De Ataíde (1964, p. 21). 
112. Arêda (s.d., p. 9).

113. De Ataíde (1948, p. 9).

114. José Bernardo da Silva $(1957$, p. 23$)$.

115. De Melo (1979, p. 2).

116. D'Almeida Filho (s.d., p. 5).

117. Cavalcanti (s.d.).

118. Santa Helena (1993).

119. Gonçalo Ferreira da Silva (2006).

120. Cavalcanti (1993).

121. Cavalcanti (1949).

122. Santa Helena (1999).

123. De Ataíde (s.d., p. 31).

124. D'Almeida Filho (s.d., p. 7).

125. De Ataíde (1950).

126. D'Almeida Filho, (s.d., p. 18).

127. Cavalcanti (s.d., p. 2).
/ Com Luiza nessa hora / E recitou 9 partes / Que o negro quase chora / E ficou cada vez mais / Encantado por Aurora"; 112 ou de se tratar de uma meretriz, Aulina "Os dedos alvos e finos / Qual teclados de piano", que consegue adquirir uma casa suntuosa "Para a sala de visita / Comprou um rico piano"; ${ }^{113}$ de Leopoldina, ${ }^{114}$ filha de marujo que toca piano; casa-se com um nobre; de Zulmira, de origem pobre, mas que aprendeu "Ler muito bem e contar / Cortar, coser, fazer flores / Tocar piano e cantar". ${ }^{115}$

A professora de piano Ester possui um pacote de virtudes que, por meio do amor, transforma até mesmo um criminoso em homem de bem: "Muito bonita e sincera, / Era um anjo em corpo humano, / Sem saber foi contemplada / Pelos olhos do tirano". ${ }^{116}$

Personagens do sexo masculino estão associadas ao piano quando se trata de pessoas muito nobres ou ricas, como o marquês Luiz de Toveira; 117 ou ainda, personalidades tidas como gênios, acima dos simples mortais, como Vinícius de Moraes, ${ }^{118}$ Fréderic François Chopin, ${ }^{119}$ Carlos Gomes ${ }^{120}$ ou Ruy Barbosa. ${ }^{121}$ Aqui aparece também Chiquinha Gonzaga, desafiando a cultura machista na sua trajetória como pianista e compositora. ${ }^{122}$

O violino, exótico

O violino é mencionado como instrumento mais raramente ouvido que o violão ou mesmo que o piano; parece tão diferenciado quanto este último, mas sem o caráter predominantemente feminino.

É lembrado num momento especial de festa, celebrando a reconciliação entre pessoas: "Abraços e mais abraços / O povo se perdoando / Era dengoso se ouvir / O povo todo falando / Ao eco do violino / A meninada dançando". ${ }^{123}$

Como o piano, não é algo que se aprende pelas ruas, mas requer um professor, uma professora. Não é instrumento fácil, requer muito tempo de dedicação, e seu aprendizado é lembrado como algo sacrificado.

Estudar violino é atividade de gente nobre como o Marquês Luiz de Tovira, "Vindo de alta linhagem / Era dotado da lira / Desde quando era menino / Tocava um violino Cravejado de safira"; 124 ou como a menina Leonor, filha da condessa Maria; ou ainda Marcela, a professora de violino que é, na verdade, a condessinha roubada. ${ }^{125}$

O som do violino é idealizado: "Adolfo puxou o arco / e tocou uma sinfonia / seu violino chorava / soluçava de agonia / era um grande repertório / que deixou quase Izidorio / em soluços com Maria"; 126 a comparação com o som do violino é usada para elogiar a voz de um cantor, Francisco Alves, que, se morreu, nos discos, "O cantor idolatrado / geme igual o violino". ${ }^{127}$

Como o piano, o violino parece um instrumento idealizado, dificilmente associado a algum personagem popular, senão a pessoas de posses, erudição e virtude. 
Apesar de semelhantes, violino e rabeca têm representações aparentemente opostas. Há uma clara distinção social do artefato violino, representante de uma urbanidade excludente, e da rabeca, segregada ao universo rural periférico e mais popular.

A rabeca: popular, mas rara

Faz-se, por 12 vezes, referência à rabeca, contudo, sem se afastar da ambientação comumente encontrada nas histórias; parece um instrumento raro, sem outra conotação.

É um instrumento originário do meio rural, contrastando com o violão, urbano, como nos versos em que alguém declara ter trocado "(...) reco-reco e rabeca por moderno violão". ${ }^{128}$

É de status comparável, ou possivelmente inferior ao da viola, e pode com ela duelar, porém com dificuldade. ${ }^{129}$

É instrumento bem mais raro em menções que a viola. Um instrumento, talvez por raro, a que, em certa ocasião, um vigarista tenta atribuir poderes mágicos de ressuscitar os mortos. ${ }^{130}$

A guitarra, portadora de uma nova era invenção do século XX.

Diversamente da guitarra, ${ }^{131}$ aqui se trata da guitarra elétrica,

Inicialmente, um sertanejo, inconformado com uma ameaça à cultura, se refere à guitarra como "irritante" 132 - sua atitude lembra aquela de Junichiro Tanizaki, autor do Elogio da sombra, um alerta à perda da cultura tradicional do Japão, com sua atemporal penumbra de luz do dia filtrada em papel de seda, pelo advento da iluminação elétrica.

A guitarra é retratada, quase sempre, associada ao meio urbano.

Ao menos dois cordéis foram feitos a respeito de Roberto Carlos, e ele aparece inseparável de sua guitarra: "O ié, ié, ié é um ritmo / que trouxe uma novidade, / a guitarra que surgiu / com toda a simplicidade, / fez de Roberto um fenômeno / na vida da mocidade". ${ }^{133}$

A guitarra inova não somente pela sua aparência, mas pela sua sonoridade, o que é mencionado como fator de surpresa no reino do céu: "Um som espalhafatoso, Alto, forte e estridente". ${ }^{134}$

Aparentemente, o maniqueísmo conhecido na Literatura de Cordel também acaba mostrando uma tensão no julgamento de Roberto Carlos, associado a um instrumento agressivo como a guitarra e conhecido por versos como "E que tudo mais vá pro (sic) inferno" e outras referências ao demônio. No entanto, predomina a imagem de bom moço, a quem se tolera alguns modos destoantes,
128. Santa Helena (1984, p. 9).

129. De Ataíde (1973, p. 5). 130. De Ataíde (1941, p. 11).

131. Denominação espanhola do violão, usada raramente como sinônimo, provavelmente para adequar rima ou prosódia.

132. Santa Helena (1984, p. 4).

133. D'Almeida Filho (s.d., p. 3).

134. D'Almeida Filho (s.d., p. 5). 
135. D'Almeida Filho (s.d., p. 5).

136. D'Almeida Filho (s.d., p. 10).

137. D'Almeida Filho (s.d., p. 4).

138. D'Almeida Filho (s.d., p. 28).

139. Cavalcanti (s.d., p. 2). como a própria cabeleira: "(...) ele com essa guitarra / cantou em muitas festanças / deu de comer e de vestir / a milhares de crianças". 135

Ao final, a guitarra é contraposta a um instrumento consagradamente celestial. Essa percepção mostra o contraste de um instrumento muito antigo e sua simbologia já aceita, certamente tendo cruzado o oceano, com um instrumento muito novo: "Deixou a guitarra fora / entrou de harpa na mão". ${ }^{136}$

Outra obra do mesmo autor considera o ídolo chegando ao inferno: "Empunhou sua guitarra e cantou: 'eu sou terrível'" o diabo acordou na marra". "137

Posteriormente, a guitarra acaba fazendo papel de uma viola: "Na guitarra nada temo / uma canção premiada / no Festival de San Remo". ${ }^{138}$

Embora não faça menção direta à guitarra, canta Rodolfo Coelho Cavalcante, em Os cabeludos de ontem e os cabeludos de hoje, uma crítica ao rock'n roll: "Quase todos os cantores / Deixaram crescer cabelos / Suas barbas e pendores, /Dando para a mocidade / Maus exemplos, na verdade, / De eróticos corruptores". ${ }^{139}$

Comentários finais

O levantamento realizado em mais de 2.000 obras da Literatura de Cordel demonstrou aspectos importantes da identidade dos instrumentos musicais junto à população cultora daquele gênero poético, predominantemente no interior e em situações subalternas nas cidades do Norte e Nordeste do Brasil.

Embora, na definição da amostra, não tenha sido buscada validade estatística, espera-se que a análise de um acervo numeroso possa ter contribuido para um melhor entendimento de como os instrumentos são socialmente representados. Esse entendimento é apresentado, de forma resumida, a seguir, em duas observações.

Uma observação geral é a da dicotomia entre dois grupos de instrumentos musicais.

Um é representado pela viola, associada à realidade da vida, à tensão entre o bem, que sempre triunfa, e o mal, que sempre renasce. É o instrumento mais comum e próximo dos protagonistas das tramas retratadas nos cordéis. A rabeca e a guitarra elétrica, de poucas menções e forma bastante distinta, parecem alinhar-se com semelhante papel. É um grupo de instrumentos ligados à condição de uma realidade vivida, em contraposição à fantasia e/ ou a uma realidade romantizada. A rabeca é ligada ao meio rural enquanto a guitarra, ao meio urbano.

Já o outro grupo compreende o violão, o piano e o violino, associados, assim como a guitarra, ao meio urbano, porém, ligados simbolicamente à educação formal e à virtude; esta aparece situada nas camadas hegemônicas da população. Não se percebe, nos poetas, sentimento de revolta, sequer consciente resignação. Até parece que, para eles, a virtude estaria no lugar que the cabe. $\bigcirc$ bandolim 
aparece em poucas menções, mas parece pertencer mais a este segundo grupo. A este grupo se pode chamar idealizado.

Uma outra observação é mais específica da viola, o instrumento mais citado e mais detalhadamente caracterizado. Instrumento adaptado de Portugal ao Brasil, foi disseminado em grande parte do território brasileiro. Com ela, encontrou-se um perfil do violeiro, o músico popular, autodidata, escolha profissional difícil, com uma incerta trajetória formativa, uma apologia do talento e do heroísmo, com certa dose de sorte.

Catullo da Paixão Cearense teria dito, da viola, "(...) eu fiz deste instrumento dos peraltas um irmão do violino e mais: do piano". Ao trazê-la para o meio urbano, despertou atenção do meio acadêmico para esse instrumento que, se não é genuinamente brasileiro na sua origem, parece o mais brasileiro pelo caráter.

A trajetória da viola brasileira pode ser mais bem compreendida e contextualizada a partir do trabalho de Elizabeth Travassos e de sua análise do caminho da viola portuguesa até o Brasil. A autora apresenta a viola, inicialmente como um instrumento urbano e, a partir da negociação e tensão posterior com a chegada do violão, evidencia sua migração para o meio rural.

Essa melhor compreensão da viola caipira, ou viola brasileira, em especial no contexto de outros instrumentos, pode ser de utilidade à causa da Luteria nacional, que, em 2009, se tornou objeto de um curso superior tecnológico ofertado na Universidade Federal do Paraná (UFPR), em Curitiba. Assim também, tal compreensão deve interessar à causa da educação musical, já que, desde 2012 , a música voltou às escolas brasileiras como conteúdo obrigatório.

Admitir que artefatos musicais possam mediar (e protagonizar) relações sociais pode colaborar para que sujeitos se identifiquem e se reconheçam como parte de um grupo.

Também pode contribuir para que sujeitos despertem um sentimento de afeto a sua produção, seus tempos, meios e seus espaços. 


\title{
REFERÊNCIAS
}

\author{
FONTES IMPRESSAS
}

FUNDAÇÃO CASA DE RUI BARBOSA. Acervo digitalizado de literatura de cordel. Disponível em <http://acervos.casaruibarbosa.gov.br/>. Acesso entre jul. 2012 e out. 2014.

JUSTA, Antonio. Apresentação. In: CAVALCANTI, Rodolfo Coelho. ABC de Guimarães Martins. Salvador: Cordel, 1973.

\section{ARTIGOS, LIVROS E TESES}

ALGERI, Nelvi Malokowsky; SIBIN, Elizabete Arcalá. A poesia trovadoresca e suas relações com a literatura de cordel e a música contemporânea. 2008. Disponível em <http://www. diaadiaeducacao.pr.gov.br/portals/pde/arquivos/810-4.pdf>. Acesso em jul. 2012.

ALVES, Aline Cristina Ribeiro. De repente: a música de improviso através do cantador popular. In: $5^{\circ}$ Encontro de Música e Mídias - E(st)éticas do som. São Paulo: USP, 2009

ARÊDA, Francisco Sales. Malassombrada peleja de Francisco Sales com o Negro Visão. [s.n.t.]. Oscar e Aurora. [s.n.t.].

BARroSO, Gustavo. Ao som da viola. Rio de Janeiro: Livraria Editora Leite Ribeiro, 1921.

BATES, Eliot. The social life of musical instruments. Ethnomusicology, v. 56, n. 3, p. 363-395, 2012.

BATISTA, Francisco das Chagas. A escrava Isaura. [s.n.t.].

BRITO, Antonio Iraildo Alves de. Poética sertaneja: aspectos do sagrado em Patativa do Assaré. 2009. Dissertação (Mestrado). Programa de Pós-Graduação em Letras, Cultura e Regionalidade. Universidade de Caxias do Sul, Caxias do Sul, 2009.

CASCUDO, Luiz da Câmara. Dicionário do folclore brasileiro. Rio de Janeiro: Itatiaia, 1993.

CAVALCANTI, Rodolfo Coelho. A discussão do artista com o médico. [s.n.t.]. . Cabeludos de ontem e cabeludos de hoje. [s.n.t.]. Carlos Gomes, o imortal brasileiro. [S.1.: s.n.]. 1993. Catullo da Paixão Cearense. [S.1.: s.n.]. 1973. 
Cuíca de Santa Amaro, o poeta popular. [s.n.t.].

Discussão de Cavalcanti com Canário. [s.n.t.].

Dr. Raimundo Araújo. [S.1.: s.n.]. 1983.

Encontro do cego Aderaldo com Rodolfo Coelho. [S.1.: s.n.]. 1957.

Mariinha Mota. [S.1.: s.n.]. 1983.

No casamento ligeiro. [s.n.t.].

Peleja de João Crispim Ramos com Rodolfo Coelho Cavalcanti. [S.1.: s.n.].1978.

Peleja de pinto com milanês. [S.1.: s.n.]. 1975.

Programa para a noite de cultura popular da Babia. [S.1.: s.n.]. 1977.

Quem ama mulber casada, em chegada de Lampião no céu. [S.1.: s.n.]. 1959.

Vida de Ruy Barbosa. [S.1.: s.n.]. 1949.

Vida e morte de Francisco Alves. [s.n.t.].

CLAYTON, Martin, HERBERT, Trevor; MIDDLETON, Richard (eds.). The Cultural Study of Music: A Critical Introduction. Nova York: Routledge, 2003, p. $274-283$.

D'ALMEIDA FILHO, Manoel. Casamento feliz. [s.n.t.].

Chegada de Roberto Carlos ao céu. [s.n.t.].

Grande combate de Neve Branca com João Cabeleira. [s.n.t.].

Jesus e o homem do surrão misterioso. [S.1.: s.n.]. 1980.

Quando o amor vence. [s.n.t.].

O encontro de Manoel d'Almeida Filbo com o Limeira da Babia. [S.1.: s.n.]. 1979.

O violeiro e a cabocla. [S.1.: s.n.]. 1958.

O violino do diabo. [s.n.t.].

Peleja de Rodolfo Coelho Cavalcanti com Manoel d'Almeida Filho. [S.1.: s.n.]. 1979.

Roberto Carlos no inferno. [s.n.t].

DA SILVA, Gonçalo Ferreira. Mena, madrinha dos poetas do Brasil. [s.n.t.].

Teodora e o império bizantino. [S.1.: s.n.]. 2006.

Annals of Museu Paulista. v. 25. n.1. Jan.-April 2017. 
DA SILVA, João Melquíades Ferreira. Peleja de Manoel Cabeceirinha com Alexandre Torto. [s.n.t.].

DA SILVA, José Bernardo. História de Juvenal e de Leopoldina. [S.1.: s.n.]. 1957.

DAWE, Kevin. The cultural study of musical instruments. In: CLAYTON, Martin, HERBERT, Trevor; MIDDLETON, Richard (eds.). The Cultural Study of Music: A Critical Introduction. Nova York: Routledge, 2003, p. $274-283$.

DE ATAÍDE, João Martins. A condessinha roubada. [S.1.: s.n.]. 1950. . A triste sorte de uma meretriz. [S.1.: s.n.]. 1948. . Casamento e mortalha no céu se talba. [s.n.t.]. . Elzira, a morta virgem. [S.1.: s.n.]. 1950. . Estória do valente sertanejo Zé Garcia. [S.1.: s.n.]. 1978. . Namoro de um cego com uma melindrosa. [S.1.: s.n.]. 1976. . O cavalo que defeca dinheiro. [S.1.: s.n.]. 1941. Peleja de Manoel Raimundo com Manoel Campina. [S.1.: s.n.]. 1947. Peleja de Manoel Riachão com o Diabo. [S.1.: s.n.]. 1951. Peleja de ventania com pedra azul. [S.1.: s.n.]. 1940. Peleja do Cégo Aderaldo com Zé Pretinho. [S.1.: s.n.]. 1973. Segundo debate de João Athayde com José Pacheco. [S.1.: s.n.]. 1939. Um amor impossível. [S.1.: s.n.]. 1951.

DO AMARAL, Firmino Teixeira. O casamento do bode com a raposa. [s.n.t.].

DIAS, Saulo Sandro Alves. O processo de escolarização da viola caipira: novos violeiros (in) ventano modas e identidades. 2010. Tese (Doutorado). Faculdade de Educação da Universidade de São Paulo - USP. São Paulo, 2010.

DIEGUES Junior, Manuel. Ciclos temáticos na literatura de cordel. In: MOREIRA, Thiers Martins (org.). Literatura popular em verso. Rio de Janeiro: Fundação Casa de Rui Barbosa, 1973.

GARCIA CANCLINI, Nestor. Culturas híbridas: estratégias para entrar e sair da Modernidade. São Paulo: Edusp, 2013. 
LAMAS, Dulce Martins. A música na cantoria nordestina. In: MOREIRA, Thiers Martins (org.). Literatura popular em verso. Rio de Janeiro: Fundação Casa de Rui Barbosa, 1973.

MAXADO; CAVALCANTI. Encontro de Maxado Nordestino com Rodolfo Cavalcanti. [S.1.: s.n.]. 1979.

MC SWAIN, Rebecca. The power of the electric guitar. Popular music and society, 19:4, 21-40, 1995.

MOREIRA, Thiers Martins (org.). Literatura popular em verso. Rio de Janeiro: Fundação Casa de Rui Barbosa, 1973.

MOSCOVICI, Serge. Representações sociais: investigações em psicologia social. Trad. Pedrinho A. Guareschi. Rio de Janeiro: Vozes, 2003.

NEGRÃO, Maria José da Trindade. Introdução à literatura de cordel. Curitiba: Letras (23): 135-152, 1975.

OLIVEIRA, Jorge Carlos Dantas. A formação da literatura de cordel brasileira. 2012. Dissertação (Mestrado). Universidade de Santiago de Compostela. Santiago de Compostela, 2012.

PACHECO, José. Já bebi, não bebo mais! Bebo até lascar o cano. [S.1.: s.n.]. 1979.

PEREIRA SOBRINHO, Manoel. A órfã de Brancamonte. [s.n.t.].

Herói de meia noite e a princesa encantada. [s.n.t.].

O casamento do calando com a lagartixa. [S.1.: s.n.]. 1959.

Os miseráveis. [s.n.t.].

QUEIROZ, Doralice Alves de. Mulheres cordelistas, percepções do universo feminino na literatura de cordel. 2006. Dissertação (Mestrado). Faculdade de Letras da Universidade Federal de Minas Gerais. Belo Horizonte, 2006.

RESENDE, José Camelo de Melo. História do poeta Ramos Patrício e Zulmira Feitosa. [S.1.: s.n.]. 1979 .

Peleja de Chica Paculú com o cego Victurino. [s.n.t.].

SANTA HELENA, Raimundo. Chiquinha Gonzaga. [S.1.: s.n.]. 1999.

Curso de cordel e repente. [S.1.: s.n.]. 1984.

Frustrações de um sertanejo. [S.1.: s.n.]. 1984.

Vinícius. [S.1.: s.n.]. 1993.

SILVA, Minelvino Francisco. História de Antônio Lisboa com a sereia. [s.n.t.]. 
. Peleja de Manoel José da Silva "Passarinho" com Apolônio Alves dos Santos. [s.n.t.].

Peleja de Zé Andorinha com João Cabeludo. [s.n.t.].

Peleja do filho do cego Aderaldo com o filho de Zé Pretinho. [s.n.t.].

SOARES, José. Choro de Leão e as piadas de Fumanchu. [S.1.: s.n.]. 1978.

Peleja de José Soares com José Costa Leite. [s.n.t.].

TRAVASSOS, Elizabeth. O destino de artefatos musicais de origem ibérica e a modernização no Rio de Janeiro (ou como a viola se tornou caipira). In: SANTOS, Gilda; VELHO, Gilberto. Artificios E Artefactos: entre o literário e o antropológico. Rio de Janeiro: 7letras, 2006.

VILELA, Ivan. O caipira e a viola brasileira. In: PAIS, José Machado; DE BRITO, Joaquim Pais; DE CARVALHO, Mário Vieira. Sonoridades Luso-Afro-Brasileiras. Lisboa: Editora da Universidade de Lisboa, 2004.

\section{ENTREVISTAS}

MOMBACH, Leandro. Luteria no Brasil. Palestra à Escola de Luteria de Markneukirchen, Westsächsische Hochschule Zwickau, Alemanha, agosto de 2010. 